\title{
Metal-metal interactions in dinuclear ruthenium complexes containing bridging 4,5-di(2-pyridyl)imidazolates and related ligands
}

\author{
Jonathan W. Slater, ${ }^{a}$ Deanna M. D’Alessandro, ${ }^{b}$ F. Richard Keene ${ }^{b}$ and Peter J. Steel $*^{a}$ \\ ${ }^{a}$ Department of Chemistry, University of Canterbury, Christchurch, New Zealand \\ Email: peter.steel@canterbury.ac.nz \\ ${ }^{b}$ School of Pharmacy \& Molecular Sciences, James Cook University, Townsville, Queensland 4811, Australia
}

\section{This submission was created using the RSC Article Template (DO NOT DELETE THIS TEXT) (LINE INCLUDED FOR SPACING ONLY - DO NOT DELETE THIS TEXT)}

The dinuclear bis(2,2'-bipyridine)ruthenium complex of 4,5-di(2-pyridyl)imidazolate has been prepared and separated into its (meso and $r a c$ ) diastereoisomers. The 2-phenyl substituted analogue forms the meso isomer selectively. All three complexes have been characterised by ${ }^{1} \mathrm{H}$ NMR and X-ray crystallography. Electrochemical measurements and spectroelectrochemistry of the mixedvalence states reveal strong metal-metal interactions and IVCT bands that are highly dependent on the electrolyte.

\section{Introduction}

For several decades, ligand-mediated metal-metal interactions have been the subject of extensive study in a variety of contexts, ranging from pure inorganic to applied biological chemistry. Much of this effort has been centred on bridging nitrogen-containing heterocyclic ligands, which are well known to facilitate interactions between metal atoms through the $\pi$ system of the ligand. ${ }^{1-3}$ Within this context ruthenium complexes of doubly-chelating bridging ligands have been particularly well studied. $^{2}$ For example, 2,2'-bipyrimidine (1) and 2,2'azobis(pyridine) (2) (Figure 1) both chelate to two metal centres and have been shown to demonstrate strong inter-metal interactions, which are particularly strong for complexes of (2). ${ }^{45}$ Numerous other bridging ligands have been reported and various explanations have been forwarded to explain the magnitude of the communication between the metal centres. Factors such as the metal-metal distance, the degree of conjugation between the metal centres and the electronic properties of the ligand and metals are generally accepted as being important. ${ }^{1,2}$ Nevertheless, there still remains much uncertainty as to what really mediates these effects.

As part of a programme involving the study of new bridging ligands, ${ }^{6}$ we described the preparations and complexes of two ligands, (3) and (4), incorporating 1,2,5-oxadiazole and 1,2,5thiadiazole bridging subunits. ${ }^{7}$ Electrochemical studies of dinuclear ruthenium complexes of these ligands revealed remarkably strong metal-metal interactions, greater than those found in the corresponding complexes of (1), despite the greater

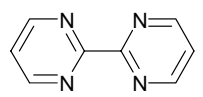

1<smiles>c1ccc(/N=N/c2ccccn2)nc1</smiles>

2
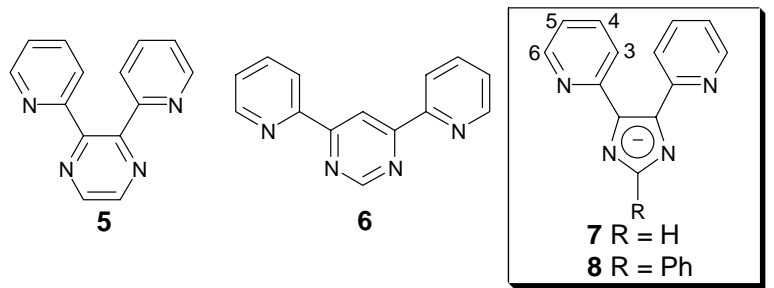

Fig.1 Bridging doubly-chelating ligands. inter-metal separation, and greater than those previously reported in complexes of 2,3-di(2-pyridyl)pyrazine (5) ${ }^{8}$ and 4,6-di(2pyridyl)pyrimidine $(6)^{9}$ despite the obvious similarities in geometry. Furthermore, we observed an intriguing difference between the magnitude of the metal-metal interactions for the two diastereoisomeric (meso and rac) forms of the dinuclear complexes containing the $\mathrm{Ru}(\mathrm{bpy})_{2}$ terminal moieties (bpy = 2,2'-bipyridine). ${ }^{7}$ Table 1 summarises these previous reports.

Table $1 \mathrm{~K}_{\mathrm{c}}$ values for dinuclear $\mathrm{Ru}(\mathrm{bpy})_{2}$ complexes of (1) - (6)

\begin{tabular}{|c|c|}
\hline Compound & $\mathrm{K}_{\mathrm{c}}{ }^{a}$ \\
\hline 1 rac $^{b}$ & 1,510 \\
\hline 1meso $^{b}$ & 1,760 \\
\hline $2 r a c^{c}$ & $283,000,000$ \\
\hline $2 m e s o^{c}$ & $192,000,000$ \\
\hline $3 r a c^{d}$ & 480,000 \\
\hline 3meso $^{d}$ & $1,220,000$ \\
\hline $4 r a c^{d}$ & 23,000 \\
\hline 4meso $^{d}$ & 29,000 \\
\hline $5^{e}$ & 747 \\
\hline $6^{e}$ & 506 \\
\hline
\end{tabular}

${ }^{a}$ Comproportionation constant, $\mathrm{K}_{\mathrm{c}}=\exp \left\{\Delta \mathrm{E}_{\mathrm{ox}} \mathrm{F} / \mathrm{RT}\right\}$, where $\mathrm{F} / \mathrm{RT}$ takes the value $38.92 \mathrm{~V}^{-1}$, in $\left[\left(n-\mathrm{C}_{4} \mathrm{H}_{9}\right)_{4} \mathrm{~N}\right] \mathrm{PF}_{6} / \mathrm{CH}_{3} \mathrm{CN}$ at $298 \mathrm{~K} .^{b}$ Values from ref. $4 \mathrm{c} .^{c}$ ref. 5 d. ${ }^{d}$ ref. $8 .{ }^{e}$ ref. 9.

In search of an explanation for the origin of this amplified communication between the metals and to ascertain whether the presence of a heteroatom in the ligand facilitates this increased interaction, we have synthesised a number of structurally-related bridging ligands for investigation. Here we report the synthesis and electrochemical properties of dinuclear ruthenium complexes of two 4,5-di(2-pyridyl)imidazolates, (7) and (8), which contain carbon atoms in place of the oxygen/sulfur atoms of the central ring, along with spectroelectrochemical studies of these and related complexes.

\section{Results and discussion}

Ligand syntheses

4,5-Diaryl- $1 H$-imidazoles are readily prepared by reaction of a 1,2-diketone with the appropriate aldehyde in the presence of a large excess of ammonium acetate in acetic acid. The preparations of the protonated forms of $(\mathbf{7})^{10}$ and $(\mathbf{8})^{11}$ have previously been described using this method, albeit in low yields. During the course of our work a more efficient synthetic route to $1 H$-imidazoles was reported ${ }^{12}$ that utilises microwave 
irradiation. We found that this method eliminated the problem of side products being formed and resulted in improved yields. In this way the parent imidazole (7) was prepared from the reaction of 2,2'-pyridil and hexamethylenetetramine as a source of formaldehyde. The 2-phenyl derivative (8) was prepared similarly from reaction between 2,2'-pyridil and benzaldehyde. In both cases using a solely thermal method resulted in the formation of significant amounts of a second major product possessing a fused imidazolo[1,5-a]pyridine ring system. ${ }^{11}$

The ligands were unambiguously characterised by NMR and mass spectrometry. An interesting feature of the NMR spectra of both compounds was the broad nature of the peaks corresponding to the four pyridyl protons. Although prototropic tautomerism of $1 \mathrm{H}$-imidazoles is normally fast on the NMR time-scale, ${ }^{13}$ this process is substantially slowed in the present compounds due to intramolecular hydrogen bonding between the $\mathrm{NH}$ hydrogen and the adjacent pyridyl nitrogen, thereby explaining the broadening of the pyridyl signals. In contrast, sharp signals are observed for the proton in the 2-position in (7) and the three peaks corresponding to the five phenyl protons in (8), which are not subject to symmetrisation by the tautomerism process.

\section{Ruthenium complexes of (7) and (8)}

Dinuclear ruthenium complexes of both the bridging ligands were conveniently synthesised from the reaction of two equivalents of $\left[\mathrm{Ru}(\mathrm{bpy})_{2} \mathrm{Cl}_{2}\right] \cdot 2 \mathrm{H}_{2} \mathrm{O}$ and the appropriate ligand. We have found a microwave-assisted method to give the shortest reaction times and the cleanest reaction products. Using this technique, reactions were carried out in ethylene glycol, with the addition of a small amount of sodium hydroxide to deprotonate the ligand, to afford the desired dinuclear products in high yields. The two diastereoisomers (9rac) and (9meso) were readily separated by column chromatography, using a method which was pioneered in one of our laboratories, ${ }^{14}$ employing SP Sephadex C-25 and aqueous $0.20 \mathrm{M}$ sodium 4-toluenesulfonate
Table $2{ }^{1} \mathrm{H}$ NMR chemical shift values ${ }^{a}$ for $(\mathbf{9})$ and $(\mathbf{1 0})$ in $\mathrm{CD}_{3} \mathrm{CN}$.

\begin{tabular}{rcccc}
\hline & H6(d) & H5(t) & H4(t) & H3(d) \\
9rac Py(a) & 7.70 & 7.21 & 8.03 & 8.51 \\
Py(b) & 8.13 & 7.61 & 8.21 & 8.54 \\
Py(c) & 7.60 & 7.25 & 7.94 & 8.41 \\
Py(d) & 7.92 & 7.47 & 8.10 & 8.56 \\
Py(e) & 7.20 & 7.18 & 8.06 & 8.53 \\
9meso Py(a) & 8.31 & 7.61 & 8.17 & 8.62 \\
Py(b) & 7.93 & 7.44 & 8.12 & 8.61 \\
Py(c) & 7.66 & 7.22 & 8.04 & 8.50 \\
Py(d) & 7.70 & 7.25 & 7.98 & 8.40 \\
Py(e) & 7.72 & 7.26 & 8.00 & 8.37 \\
10meso Py(a) & 7.80 & 7.41 & 8.03 & 8.26 \\
Py(b) & 6.99 & 6.67 & 7.51 & 7.95 \\
Py(c) & 7.58 & 7.20 & 8.06 & 8.64 \\
Py(d) & 8.54 & 7.79 & 8.19 & 8.54 \\
Py(e) & 7.59 & 7.32 & 8.01 & 8.47 \\
For atom labelling, see Fig. 1. & & & \\
\hline
\end{tabular}

solution as eluent. The ${ }^{1} \mathrm{H}$ NMR spectra of these isomers showed the proton in the 2-position on the imidazole ring to be shifted considerably upfield, due to shielding by the adjacent pyridine rings of two different bipyridyl ligands. This proved to be a useful handle in the identification of the two isomers, as this proton occurs at $5.98 \mathrm{ppm}$ in the rac isomer and $5.68 \mathrm{ppm}$ in the meso isomer due to the greater extent of the shielding effect in the latter isomer. Figure 2 shows the NMR spectra of (9rac) and (9meso) along with that of the crude mixture for comparison. For each isomer the ${ }^{1} \mathrm{H}$ NMR signals were readily grouped (Table 2 ) into the five separate pyridine rings $[\mathrm{Py}(\mathrm{a})-(\mathrm{d})]$ by means of 1D-TOCSY and/or 2D-COSY spectra but the specific rings within the structure could not be unambiguously distinguished.

The structures of the two isomers were further confirmed by $\mathrm{X}$-ray crystallography. In both cases it was possible to grow crystals suitable for X-ray diffraction by slow evaporation of a acetonitrile:toluene solution of the complex. The rac isomer (9rac) crystallises as thin red plates in the chiral trigonal space group $\mathrm{P}_{1} 21$, with a full dinuclear cation in the asymmetric unit along with two full and two half $\mathrm{PF}_{6}^{-}$anions, the latter lying on

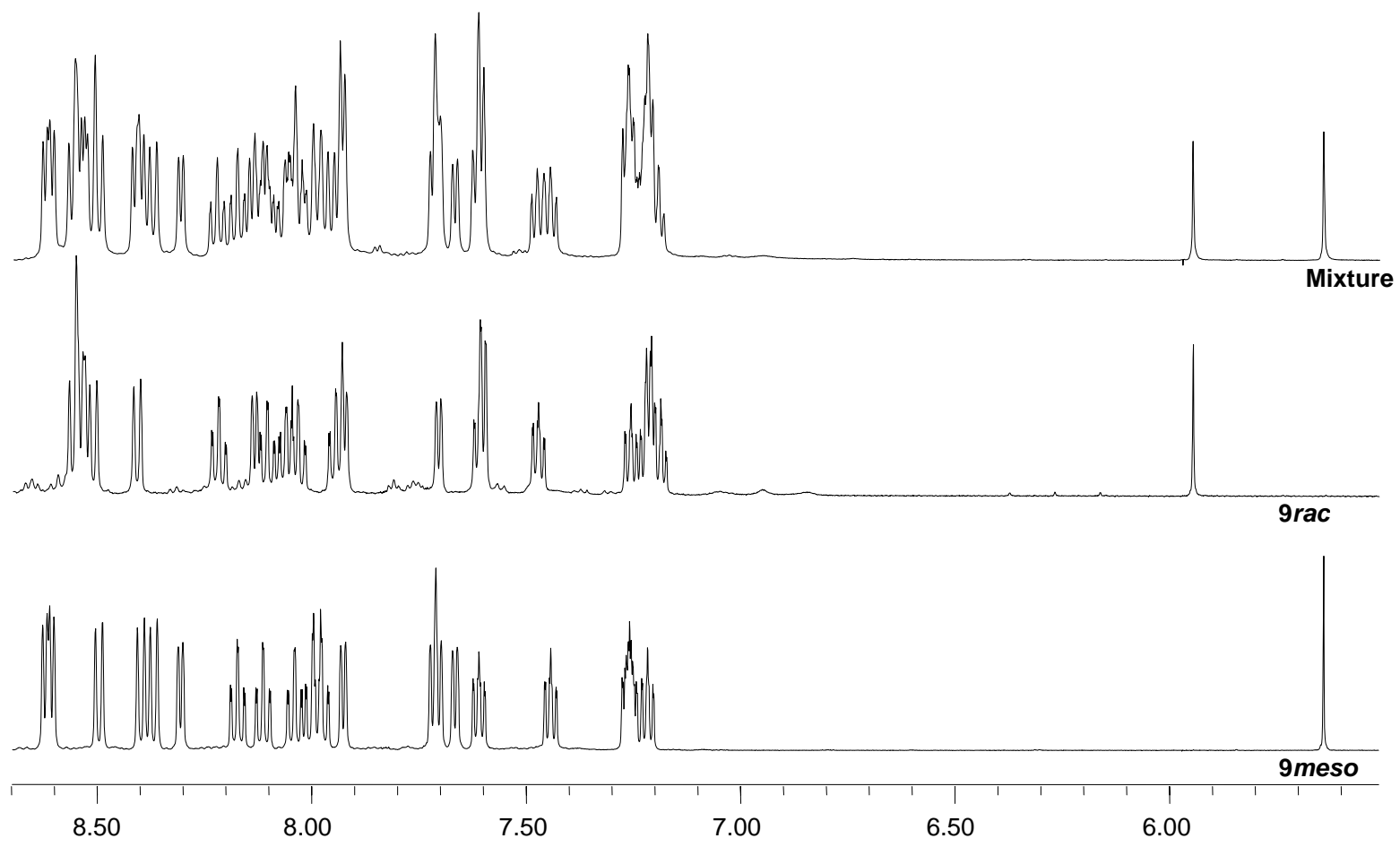

Fig. 2 NMR spectra of (9) showing the mixture and the two isomers after separation. 

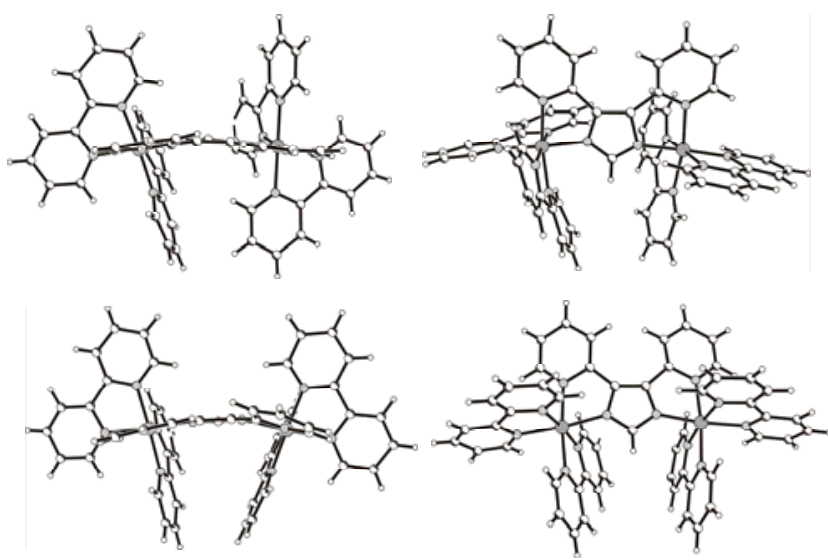

Fig.3 Perspective views of (9rac), top, and (9meso), bottom.

crystallographic two-fold rotation axes. The meso isomer (9meso) crystallised as red needles in the triclinic space group P1 , with a full dinuclear cation in the asymmetric unit along with three $\mathrm{PF}_{6}{ }^{-}$anions (one being disordered), an acetonitrile and one and a half toluene solvate molecules (the last being disordered about a centre of inversion). Figure 3 shows two perspective views of each isomer (9rac) and (9meso), which serves to show the very different shapes of these two stereoisomers.

When we attempted to synthesise dinuclear complexes of (8) we observed the formation of the meso isomer (10meso) only. The X-ray crystal structure of this compound was also determined. It crystallises in the orthorhombic space group Cmca with the dinuclear cation lying on a crystallographic mirror plane passing through $\mathrm{C} 2$ of the imidazole ring and the attached phenyl ring. The asymmetric unit also contains two half $\mathrm{PF}_{6}^{-}$anions (one on a two-fold rotation axis and the other on a mirror plane), two quarter $\mathrm{PF}_{6}^{-}$anions (one on a site of $2 / \mathrm{m}$ symmetry) and a highly disordered toluene solvate molecule. A space-filling diagram of the dinuclear cation (10meso) is shown in Figure 4. This shows that the central phenyl ring is neatly sandwiched between two pyridine rings of bpy ligands that are significantly bowed towards one another. This deformation results from a curvature of the bridging ligand which is substantially nonplanar. The selective formation of a single diastereoisomer is unusual for such complexes ${ }^{15}$ and probably occurs in this case to maximise the observed $\pi-\pi$ stacking of the aryl rings and minimise unfavourable steric interactions that would exist in the corresponding rac isomer.

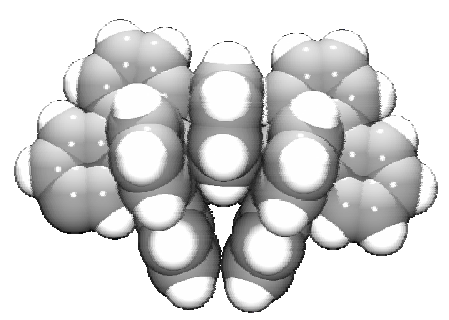

Fig. 4 Space-filling diagram of (10meso).

\section{Electrochemistry}

In order to probe the metal-metal communication between the ruthenium centres in complexes (9) and (10) electrochemical studies were carried out. As noted above, the two diastereoisomers of complexes of ligands (3) and (4) were found to display unusally different $\mathrm{K}_{\mathrm{c}}$ values. The corresponding complexes of ligands (5) and (6) have only been previously measured as mixtures of isomers and various values of $\mathrm{K}_{\mathrm{c}}$ have been reported for the complexes of (5). ${ }^{3} \mathrm{We}$ therefore decided to separate these compounds into the rac and meso isomers and measure the $\mathrm{K}_{\mathrm{c}}$ values of the individual isomers. The redox potentials for the complexes (5rac), (5meso), (6rac) and (6meso) are listed in Table 3 . The $\mathrm{K}_{\mathrm{c}}$ values for the two stereoisomers of the complexes of (5) are identical and at the high end of the range of values previously reported for the mixture of diastereoisomers. ${ }^{3}$ The $\mathrm{K}_{\mathrm{c}}$ values for (6rac) and (6meso) are significantly lower and do show a measurable difference between the two isomers. Table 3 also shows the results for the three complexes which are the focus of this study, along with data for $\left[\mathrm{Ru}(\mathrm{bpy})_{3}\right]^{2+}$ as a comparison. Redox potentials of complexes (9) and (10) are cathodically shifted relative to $\left[\mathrm{Ru}(\mathrm{bpy})_{3}\right]^{2+}$ due to the anionic nature of the bridging ligand.

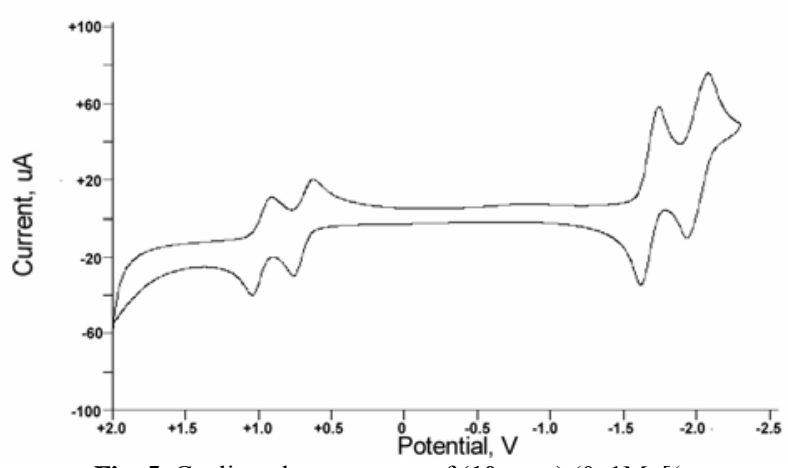

Fig. 5 Cyclic voltammogram of (10meso) $(0.1 \mathrm{M}[(n-$ $\left.\left.\mathrm{C}_{4} \mathrm{H}_{9}\right)_{4} \mathrm{~N}\right] \mathrm{PF}_{6} / \mathrm{CH}_{3} \mathrm{CN}$ : Pt working electrode; vs. $\mathrm{FeCp}_{2}{ }^{+} / \mathrm{FeCp}_{2}{ }^{0}$ )

For the three complexes (9rac), (9meso) and (10meso) in $\left[\left(n-\mathrm{C}_{4} \mathrm{H}_{9}\right)_{4} \mathrm{~N}\right] \mathrm{PF}_{6} / \mathrm{CH}_{3} \mathrm{CN}$ media we see a considerable separation between the redox couples associated with the first two reversible oxidation processes. Such separations are associated with high $\mathrm{K}_{\mathrm{c}}$ values and thus we can infer a high degree of communication between the two metal centres. Figure 5 shows the cyclic voltammogram for complex (10meso), which is typical for these complexes. The magnitudes of the $\mathrm{K}_{\mathrm{c}}$ values lie between those previously found for the corresponding complexes of ligands (3) and (4). Once again a significant difference is observed between the rac and meso isomers of (9).

A second set of measurements were carried out, again in acetonitrile solution, but this time using the electrolyte tetra $(n-$ butyl)ammonium tetrakis(pentafluorophenyl)borate, [(n$\left.\left.\mathrm{C}_{4} \mathrm{H}_{9}\right)_{4} \mathrm{~N}\right] \mathrm{B}\left(\mathrm{C}_{6} \mathrm{~F}_{5}\right)_{4} \cdot{ }^{16}$ Under these conditions, higher values of $\mathrm{K}_{\mathrm{c}}$ were observed, but the $\mathrm{K}_{\mathrm{c}}$ values for the diastereoisomers (9rac)

Table 3 . Redox potentials and $\mathrm{K}_{\mathrm{c}}$ values for the stereoisomers of compounds (5), (6), (9) and (10) compared to $\operatorname{Ru}(\mathrm{bpy})_{3}{ }^{2+}$

\begin{tabular}{|c|c|c|c|c|c|c|c|c|}
\hline Compound & Electrolyte & $\Delta \mathrm{E}_{\mathrm{ox}}{ }^{\mathrm{a}}$ & $E_{0 \times 2}$ & $E_{o x 1}$ & $\mathrm{E}_{\text {red } 1}$ & $\mathrm{E}_{\mathrm{red} 2}$ & $E_{\text {red3 }}$ & $\mathrm{K}_{\mathrm{c}}{ }^{b}$ \\
\hline 5rac & $\mathrm{PF}_{6}^{-}$ & 212 & 1244 & 1032 & -1048 & -1560 & -1888 & 3830 \\
\hline 5 meso & $\mathrm{PF}_{6}^{-}$ & 212 & 1256 & 1044 & -1044 & -1540 & -1900 & 3830 \\
\hline 6rac & $\mathrm{PF}_{6}^{-}$ & 690 & 1208 & 1040 & -892 & -1524 & -1920 & 690 \\
\hline 6meso & $\mathrm{PF}_{6}^{-}$ & 506 & 1220 & 1060 & -876 & -1500 & -1924 & 506 \\
\hline 9rac & $\mathrm{PF}_{6}^{-}$ & 344 & 884 & 540 & -1800 & -2064 & -2548 & 652,000 \\
\hline 9meso & $\mathrm{PF}_{6}^{-}$ & 312 & 844 & 532 & -1824 & -2052 & -2528 & 188,000 \\
\hline 10 meso & $\mathrm{PF}_{6}^{-}$ & 276 & 836 & 560 & -1816 & -2153 & ---- & 46,200 \\
\hline 9rac & $\mathrm{B}\left(\mathrm{C}_{6} \mathrm{~F}_{5}\right)_{4}^{-}$ & 347 & 931 & 584 & -1832 & -2310 & --- & 733,000 \\
\hline 9meso & $\mathrm{B}\left(\mathrm{C}_{6} \mathrm{~F}_{5}\right)_{4}^{-}$ & 341 & 941 & 592 & -1840 & -2104 & ---- & 793,000 \\
\hline$\left[\mathrm{Ru}(\mathrm{bpy})_{3}\right]^{2+}$ & $\mathrm{PF}_{6}^{-}$ & ---- & ---- & 950 & -1640 & -1820 & -2080 & --- \\
\hline
\end{tabular}

${ }^{a} \Delta \mathrm{E}_{\mathrm{ox}}=\mathrm{E}_{\mathrm{ox} 2}-\mathrm{E}_{\mathrm{ox} 1 .}{ }^{b}$ Comproportionation constant, $\mathrm{K}_{\mathrm{c}}=\exp \left\{\Delta \mathrm{E}_{\mathrm{ox}} \mathrm{F} / \mathrm{RT}\right\}$, where $\mathrm{F} / \mathrm{RT}$ takes the value $38.92 \mathrm{~V}^{-1}$ at $298 \mathrm{~K}$. 
and (9meso) were now very similar. The greater separation of the potentials associated with the oxidation processes, and the resultant higher $\mathrm{K}_{\mathrm{c}}$ values, obtained in $\mathrm{B}\left(\mathrm{C}_{6} \mathrm{~F}_{5}\right)_{4}{ }^{-}$compared with $\mathrm{PF}_{6}{ }^{-}$media is not unexpected and reflects a higher association of the latter anion with the cations, which in turn lowers the potential of the oxidation processes. ${ }^{5 \mathrm{~d}}$ This lowering of the potential is more pronounced for the second oxidation process as the charges are greater, thus lowering $\Delta \mathrm{E}_{\mathrm{ox}}$. In $\mathrm{B}\left(\mathrm{C}_{6} \mathrm{~F}_{5}\right)_{4}{ }^{-}$media, the association is very much less, and apparently does not differ significantly between the two diastereoisomers (9rac) and (9meso). The fact that a difference in $\Delta \mathrm{E}_{\mathrm{ox}}$ is observed between the diastereoisomers in $\mathrm{PF}_{6}^{-}$media reflects the fact that where association is present, its extent is different between the diastereoisomers giving rise to different values of $\Delta \mathrm{E}_{\mathrm{ox}}$.

It is interesting to note (Table 3) that the $\Delta \mathrm{E}_{\mathrm{ox}}$ values for the rac diastereoisomer (9rac) are virtually the same in both media, whereas they differ significantly for the meso form (9meso). This is consistent with the proposal that there is considerable ion association between the $\mathrm{PF}_{6}{ }^{-}$anion and the meso diastereoisomer in particular. This is the isomer with a substantially larger cavity, above and below the plane of the bridging ligand, that can accommodate the anion (Fig. 3).

A recent publication $^{17}$ has warned about the use of electrochemically-derived $\mathrm{K}_{\mathrm{c}}$ values as a means of measuring metal-metal communication, due to the effect of ion pairing. In the present case, the differences in $\Delta \mathrm{E}_{\mathrm{ox}}$ (and therefore $\mathrm{K}_{\mathrm{c}}$ ) determined in the two media reflect differences in ion association rather than inter-metal communication. For even more strongly associating anions, such as 4-toluenesulfonate, the differential association can be quite profound, a fact that we actually use to our advantage when separating the two isomers by cation exchange chromatography.

For complexes (9) and (10) we see two $2 \mathrm{e}^{-}$reversible reduction processes that correspond to reduction of two different bpy rings. With dinuclear ruthenium complexes containing $\pi$ deficient diazine briding ligands, such as (1), (5) and (6), the first reduction usually involves electron transfer into the bridging ligand. ${ }^{1,2}$ However, the imidazolate ring is a $\pi$-excessive system with a much higher energy LUMO orbital. Thus the bpy ligands are the first to be reduced. In compounds (9rac) and (9meso) a subsequent $1 \mathrm{e}^{-}$reduction was observed that corresponds to reduction of the bridging ligand. When using the $\mathrm{B}\left(\mathrm{C}_{6} \mathrm{~F}_{5}\right)_{4}^{-}$ counterion, this reduction was beyond the limits of the solvent system.

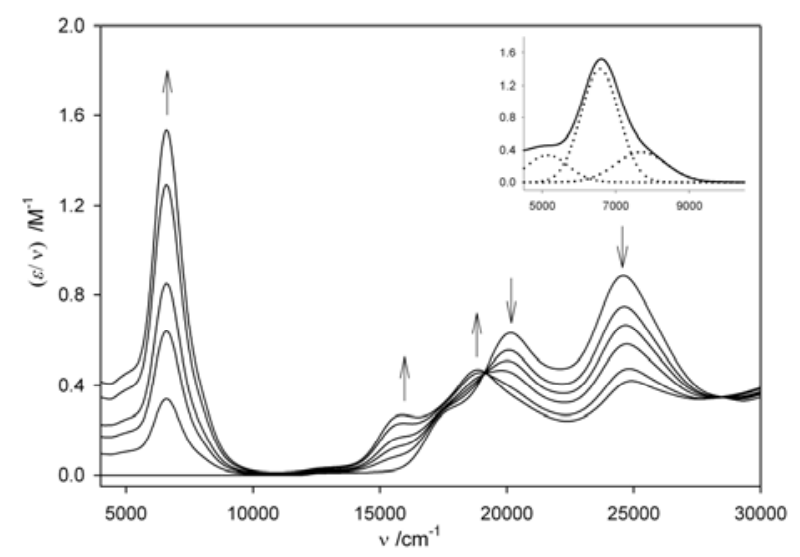

(a)

\section{Spectroelectrochemistry}

The UV/Vis spectral properties of the $4+$ forms of the complexes of (3) and (4) have been described previously, ${ }^{7}$ but no spectroelectrochemical studies were carried out. As part of the present study, we have now recorded the UV/Vis/NIR spectra for the diastereoisomers of (3) ${ }^{n+}$ and $(4)^{n+}\{n=4,5,6\}$ over the range $3050-30000 \mathrm{~cm}^{-1}$ (Electronic Supplementary Information, Table S1). The spectral progression accompanying the oxidation of $(3 m e s o)^{4+}$ to (3meso) $)^{5+}$ in $0.1 \mathrm{M}\left[\left(n-\mathrm{C}_{4} \mathrm{H}_{9}\right)_{4} \mathrm{~N}\right] \mathrm{PF}_{6} / \mathrm{CH}_{3} \mathrm{CN}$ at $-35^{\circ} \mathrm{C}$ is shown in Figure 6(a). The lowest energy absorption bands in the spectra of the $4+$ species are assigned as $d \pi(\mathrm{Ru}) \rightarrow$ $\pi^{*}(\mathrm{BL}) \mathrm{MLCT}$ transitions. These bands decreased in energy and intensity following one-electron oxidation to the mixed-valence (5+) species, and collapsed completely on further oxidation to the $6+$ state. The new bands in the regions $3050-9000 \mathrm{~cm}^{-1}$ and $14000-16000 \mathrm{~cm}^{-1}$ in the mixed-valence species are assigned as IVCT and LMCT transitions, respectively. The former are absent in the spectra of the $6+$ species, while the latter increase in intensity, and are consistent with the $\pi($ bpy $) \rightarrow \mathrm{d} \pi\left(\mathrm{Ru}^{\mathrm{III}}\right)$ LMCT transitions at 14815 and $17160 \mathrm{~cm}^{-1}$ in $\left[\mathrm{Ru}^{\mathrm{III}}(\mathrm{bpy})_{3}\right]^{3+18}$ Comparable behaviour was observed for $(3 \mathbf{r a c})^{n+}$, and for the two diastereoisomers of $(4)^{n+}$.

The UV/Vis/NIR spectral properties for the diastereoisomers of $(9)^{n+}\{n=3,4,5\}$ in $0.1 \mathrm{M}\left[\left(n-\mathrm{C}_{4} \mathrm{H}_{9}\right)_{4} \mathrm{~N}\right] \mathrm{PF}_{6} / \mathrm{CH}_{3} \mathrm{CN}$ and 0.02 $\mathrm{M}\left[\left(n-\mathrm{C}_{4} \mathrm{H}_{9}\right)_{4} \mathrm{~N}\right] \mathrm{B}\left(\mathrm{C}_{6} \mathrm{~F}_{5}\right)_{4} / \mathrm{CH}_{3} \mathrm{CN}$ at $-35^{\circ} \mathrm{C}$ are reported in Table $\mathrm{S} 2$, and the spectra of $(9 \mathrm{rac})^{n+}$ in $\mathrm{PF}_{6}{ }^{-}$media are shown in Figure S1 (Electronic Supplementary Information). The MLCT transitions exhibited similar behaviour on oxidation to that described for $(3)^{n+}$ and $(4)^{n^{+}}$. The mixed-valence $(4+)$ state is characterised by two new bands in the regions $3050-8000 \mathrm{~cm}^{-1}$ and $8000-15000 \mathrm{~cm}^{-1}$ which are assigned as IVCT and LMCT transitions, respectively. Further oxidation to the $5+$ species causes a disappearance of the IVCT band, and a blue-shift in the LMCT band. While the latter contradicts the expected red-shift in LMCT bands with oxidation, similar behaviour has been observed for other dinuclear ruthenium complexes incorporating anionic bridging ligands such as 3,5-bis(pyrazin-2-yl)-1,2,4triazolate. ${ }^{19}$ In contrast to $(3)^{n^{+}}$and $(4)^{n^{+}}$in which electron transfer involves a superexchange-assisted electron transfer mechanism via the $\pi, \pi^{*}$ bridging ligand orbitals, the lowest energy orbitals (LUMOs) of $(\mathbf{9})^{\boldsymbol{n}^{+}}$lie relatively high in energy. As a result, hole transfer via the highest occupied molecular orbitals (HOMOs) of the bridging ligand is the dominant electron transfer pathway. These observations are corroborated by the electrochemical data which show that the first reduction is

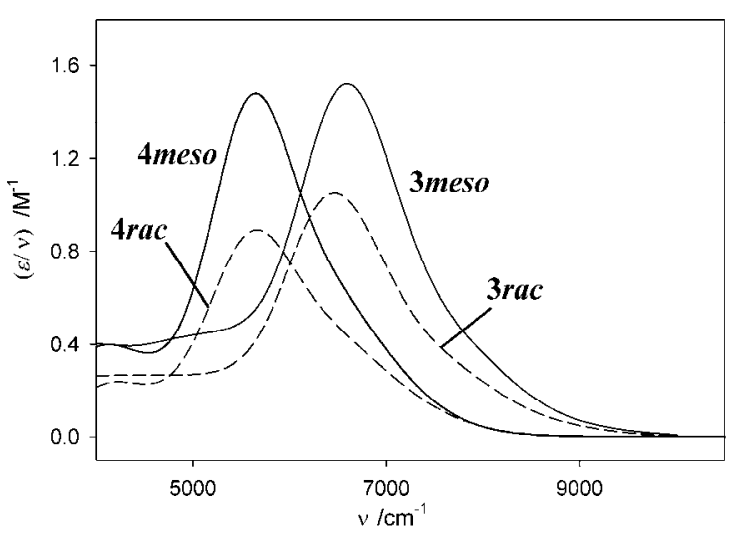

(b)

Fig. 6 (a) Spectral progression for the oxidation reaction (3meso) $)^{4+} \rightarrow(3 m e s o)^{5+}$ in $0.1 \mathrm{M}\left[\left(n-\mathrm{C}_{4} \mathrm{H}_{9}\right)_{4} \mathrm{~N}\right] \mathrm{PF}_{6} / \mathrm{CH}_{3} \mathrm{CN}$ at $-35^{\circ} \mathrm{C}$. The inset shows the best fit Gaussian deconvolution of the IVCT band. (b) NIR spectra for both isomers of $(3)^{5+}$ and $(4)^{5+}$ in $0.1 \mathrm{M}^{2}\left[\left(n-\mathrm{C}_{4} \mathrm{H}_{9}\right)_{4} \mathrm{~N}\right] \mathrm{PF}_{6} / \mathrm{CH}_{3} \mathrm{CN}$ at $-35^{\circ} \mathrm{C}$. 
bpy-based in $(\mathbf{9})^{n^{+}}$, rather than bridging ligand-based as is the case for $(3)^{n+}$ and $(4)^{n+}$.

Figure 6(b) shows the NIR bands for the diastereoisomers of $(3)^{5+}$ and $(4)^{5+}$ (in $\mathrm{PF}_{6}^{-}$media), and Figure 7 shows the NIR bands for the diastereoisomers of $(\mathbf{9})^{4+}$ (in $\mathrm{PF}_{6}^{-}$and $\left.\mathrm{B}_{\left(\mathrm{C}_{6}\right.} \mathrm{F}_{5}\right)_{4}^{-}$ media). The energy $\left(v_{\max }\right)$, intensity $\left\{(\varepsilon / v)_{\max }\right\}$, bandwidth $\left(\Delta v_{1 / 2}\right)$ and the band area (zeroth-moment, $\left.M_{0}\right)$ for the IVCT bands are reported in Table 4 . The parameters for the bands obtained from Gaussian deconvolution of the manifolds are reported in Tables S2 (for $(3)^{5+}$ and $(4)^{5+}$ ) and S3 (for $(9)^{4+}$ ), Electronic Supplementary Information. In each case, the IVCT bands were fitted by three Gaussian-shaped components, denoted IVCT(1), (2) and (3) in order of increasing energy; however IVCT(1) was obscured at the detector limit for $(\mathbf{9})^{4+}$. The LMCT bands for $(\mathbf{9})^{4+}$ were also fitted by three Gaussian components. For all complexes, IVCT(2) exhibited the highest intensity and dominated the IVCT manifold.

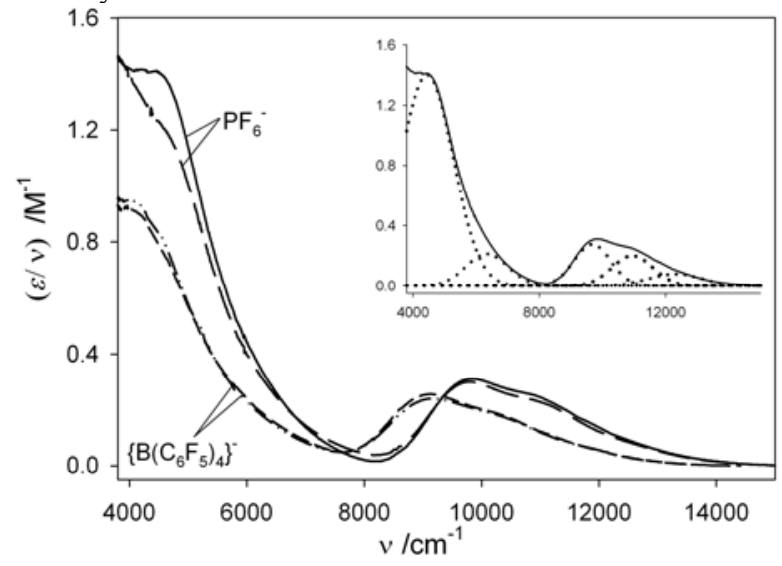

Fig. 7. NIR spectra for $(\mathbf{9})^{4+}$ in $0.1 \mathrm{M}\left[\left(n-\mathrm{C}_{4} \mathrm{H}_{9}\right)_{4} \mathrm{~N}\right] \mathrm{PF}_{6} / \mathrm{CH}_{3} \mathrm{CN}$ \{meso $(-)$, rac (---)\} and $0.02 \mathrm{M}\left[\left(n-\mathrm{C}_{4} \mathrm{H}_{9}\right)_{4} \mathrm{~N}\right] \mathrm{B}\left(\mathrm{C}_{6} \mathrm{~F}_{5}\right)_{4} / \mathrm{CH}_{3} \mathrm{CN}$ \{meso (-----), rac $(-. \cdot-)\}$ at $-35^{\circ} \mathrm{C}$. The inset shows the best fit Gaussian deconvolution of $(7 \mathrm{rac})^{4+}$ in $0.1 \mathrm{M}\left[\left(n-\mathrm{C}_{4} \mathrm{H}_{9}\right)_{4} \mathrm{~N}\right] \mathrm{PF}_{6} / \mathrm{CH}_{3} \mathrm{CN}$.

The three IVCT components arise due to separate electronic excitations from one of the three $\mathrm{d} \pi_{\mathrm{n}}(\mathrm{n}=1-3)$ orbitals at $\mathrm{Ru}^{\mathrm{II}}$ to the hole in the corresponding $\mathrm{d} \pi_{\mathrm{n}}$ orbital which is present in any of the three spin-orbit states at $\mathrm{Ru}^{\text {III }} .22$ The magnitude of the separation between the components $\left(c a .1000 \mathrm{~cm}^{-1}\right)$ is consistent with the energy splittings between the three $d \pi_{n}$ orbitals which arise due to the combined effects of spin-orbit coupling $(\xi \sim 1100$ $\mathrm{cm}^{-1}$ for $\left.\mathrm{Ru}^{\text {III }}\right)^{23}$ and ligand-field asymmetry. If the $x y$ plane defines the plane of the bridging ligands and $z$ lies perpendicular to the plane, the three $\mathrm{d} \pi_{\mathrm{n}}$ orbitals may be more closely represented by $d_{x z}, d_{y z}\left(d \pi_{1}, d \pi_{2}\right)$ and $d_{x y}\left(d \pi_{3}\right)$. The enhanced stabilisation of the former due to the relatively greater overlap with the $\pi, \pi^{*}$ orbitals of the bridging ligands, accounts for the higher intensity of IVCT(2) relative to IVCT(3).

For all complexes, the bandwidths are narrow compared with the theoretical predictions for $\Delta v_{1 / 2}{ }^{\circ}$, which together with the significant intensity of the NIR manifolds suggest that the systems are delocalised (Class III). The IVCT components are more accurately assigned as transitions between bonding and non-bonding orbitals within the molecular orbital manifolds of the dinuclear complexes, as described within the three-state model of Ondrechen, and illustrated schematically in Figure S2. ${ }^{24}$ For $(3)^{5+}$ and $(4)^{5+}$, the salient feature of the model is the $\mathrm{d} \pi \rightarrow \pi^{*}(\mathrm{BL})$ energy gap, which is larger for the former due to its enhanced $\pi$-acceptor nature. ${ }^{7}$ The relatively greater separation between the bonding and non-bonding orbitals is manifested as a blue-shift in the NIR band for $(3)^{5+}$ relative to $(4)^{5+}$. For delocalised mixed-valence complexes, the energy of the NIR transition provides a direct measure of the electronic coupling parameter, $H_{a b}\left(H_{a b}=1 / 2 v_{\max }\right.$, Table 4). ${ }^{22}$

As shown in Table 4, the parameters of the NIR bands differ for the same diastereoisomer of $(3)^{5+}$ and $(4)^{5+}$, and between the two diastereoisomeric forms of the same complex. For both complexes, the integrated intensity of the manifold is greater for the meso relative to the rac forms. X-ray structural studies ${ }^{7}$ revealed comparable inter-metal distances for the diastereoisomers of $(3)^{5+}\{6.016 \AA$ for meso, $6.014 \AA$ for rac $\}$ which would be similar for $(4)^{5+}$. The differences in the IVCT parameters between the diastereoisomers of the same complex are ascribed to differential ion-pairing interactions and specific solvation effects. The $\mathrm{H}_{\mathrm{ab}}$ values suggest that for a given diastereoisomer, $(3)^{5+}$ exhibits greater electronic coupling relative to $(4)^{5+}$. The degree of aromaticity of the bridge has been postulated to facilitate electronic coupling between metal centres. The 1,2,5-oxadiazole system has a low degree of aromaticity and high "diene" character, with the electronegative oxygen atom contributing little of its electron density into the ring. ${ }^{25}$ Since sulfur is less electronegative than oxygen and does not reduce the electron density of the ruthenium centres to the same extent, $(4)^{5+}$ would be expected to be a more delocalised system because of the greater polarisability of the larger sulfur atom. However, the relatively low aromatic character of the bridge in $(3)^{5+}$ has not restricted the electronic communication between the metals. In fact, the low aromatic character has served to enhance the electronic coupling, as exemplified by the higher $\mathrm{H}_{\mathrm{ab}}$ values in $(3)^{5+}$.

While the diastereoisomers of $(\mathbf{9})^{4+}$ exhibit comparable band parameters to one another in each electrolyte system, the characteristics of the IVCT and LMCT bands are markedly

Table 4 NIR spectral data of the reduced absorption spectra $\left(\varepsilon / v\right.$ vs. v) for $(3)^{5+},(\mathbf{4})^{5+}$ and $(\mathbf{9})^{4+}$ in $0.1 \mathrm{M}\left[\left(n-\mathrm{C}_{4} \mathrm{H}_{9}\right)_{4} \mathrm{~N}\right] \mathrm{PF}_{6} / \mathrm{CH}_{3} \mathrm{CN}$ and $(\mathbf{9})^{5+}$ in $0.02 \mathrm{M}[(n-$ $\left.\left.\mathrm{C}_{4} \mathrm{H}_{9}\right)_{4} \mathrm{~N}\right] \mathrm{B}\left(\mathrm{C}_{6} \mathrm{~F}_{5}\right)_{4} / \mathrm{CH}_{3} \mathrm{CN}$ at $-35^{\circ} \mathrm{C}$.

\begin{tabular}{|c|c|c|c|c|c|c|c|}
\hline Electrolyte & Complex & $\begin{array}{l}v_{\max } \\
\pm 10 \\
/ \mathrm{cm}^{-1}\end{array}$ & $\begin{array}{c}(\varepsilon / v)_{\max } \\
\pm 0.0001 \\
/ \mathrm{M}^{-1}\end{array}$ & $\begin{array}{l}\Delta v_{1 / 2}^{a} \\
\pm 20 \\
/ \mathrm{cm}^{-1}\end{array}$ & $\begin{array}{l}\Delta v_{1 / 2}{ }^{\mathrm{o}} \\
/ \mathrm{cm}^{-1}\end{array}$ & $\begin{array}{c}M_{0} \\
/ \mathrm{M}^{-1}\end{array}$ & $\begin{array}{l}\mathrm{H}_{\mathrm{ab}}{ }^{\mathrm{d}} \\
/ \mathrm{cm}^{-1}\end{array}$ \\
\hline \multirow[t]{6}{*}{$\mathrm{PF}_{6}^{-}$} & $3^{m e s o}{ }^{5+}$ & 6590 & 1.5218 & 1470 & 3480 & 3211 & 3295 \\
\hline & $3 r a c^{5+}$ & 6460 & 1.2737 & 1492 & 3440 & 2650 & 3230 \\
\hline & $4 m e s o^{5+}$ & 5625 & 1.4908 & 1346 & 3210 & 2538 & 2813 \\
\hline & $4 \mathrm{rac}^{5+}$ & 5628 & 0.8995 & 1516 & 3215 & 1656 & 2814 \\
\hline & 9a $\mathrm{rac}^{4+}$ & 4475 & 1.4816 & $1112^{b}$ & 2866 & c & 2238 \\
\hline & $9 \mathrm{~b}$ meso $^{4+}$ & 4560 & 1.2061 & $1029^{b}$ & 2893 & c & 2280 \\
\hline \multirow[t]{2}{*}{$\mathrm{B}\left(\mathrm{C}_{6} \mathrm{~F}_{5}\right)_{4}^{-}$} & 9a $\mathrm{rac}^{4+}$ & 4120 & 0.9668 & $1148^{\mathrm{b}}$ & 2750 & c & 2060 \\
\hline & $9 \mathrm{~b}$ meso $^{4+}$ & 4105 & 0.9119 & $1160^{\mathrm{b}}$ & 2745 & c & 2053 \\
\hline
\end{tabular}

${ }^{a} \Delta v_{1 / 2}{ }^{o}=\left[1836\left(v_{\max }\right)\right]^{1 / 2}$ at $238 \mathrm{~K} .{ }^{20}{ }^{\mathrm{b}}$ Bandwidth for the high-energy side of the IVCT manifold. The lower energy side was obscured at the detector limit. ${ }^{\mathrm{c}}$ The $M_{0}$ for the full band manifold could not be measured reliably. ${ }^{\mathrm{d}} \mathrm{H}_{\mathrm{ab}}$ determined as $1 / 2 v_{\max },{ }^{20}$ assuming that the complexes are delocalised (Class III). ${ }^{21}$ 
dependent on the identity of the electrolyte counter-ion. In $\mathrm{B}\left(\mathrm{C}_{6} \mathrm{~F}_{5}\right)_{4}{ }^{-}$media, the IVCT bands are red-shifted and narrower and the parameters $(\varepsilon / v)_{\max }, M_{0}$ and $\mathrm{H}_{\mathrm{ab}}$ are decreased compared with their values in $\mathrm{PF}_{6}{ }^{-}$electrolyte. Ion-pairing effects have been shown to influence the IVCT characteristics in a number of dinuclear ruthenium ${ }^{26}$ and iron $^{27}$ systems. Qualitatively, the experimental observations in the present study are similar to these previous literature reports which have shown that IVCT bands are blue-shifted in the presence of relatively strongly ionpairing electrolytes $\left(\mathrm{PF}_{6}^{-}\right.$in the present case). The effect is attributed to ion-pair formation which induces an additional energy contribution to $v_{\max }$. The results show that in $(\mathbf{9})^{4+}$ the significant electronic communication between the metal centres is most likely to occur via the highest occupied molecular orbital HOMO of the bridging ligand, rather than the LUMO in the case of $(3)^{5+}$ and $(4)^{5+}$. In addition, the electronic coupling is enhanced in the presence of a stronger ion-pairing electrolyte $\left(\mathrm{PF}_{6}^{-}\right)$.

\section{Conclusions}

The results reported here show that it is not the inclusion of a heteroatom in the aromatic ring system that is inherently responsible for the amplification in metal-metal communication we observe in such systems. There is no obvious trend in the degree of communication as we move from imidazolate- to oxadiazole- to thiadiazole-bridge. It should perhaps be noted that the imidazolate bridge is in fact anionic, while both the oxadiazole and thiadazole are neutral and so care should be taken when making direct comparisons. Nevertheless, it would appear that the inclusion of a five-membered ring in the bridge is the most important factor for such strong inter-metal communication. Furthermore, beyond a broad consideration of intermetallic distances, it would not appear to be possible to accurately predict the extent of communication in any particular bridging ligand system.

\section{Experimental}

\section{General}

${ }^{1} \mathrm{H}$ NMR experiments were performed on a Varian INOVA $500 \mathrm{MHz}$ NMR spectrometer at room temperature. ${ }^{1} \mathrm{H}$ NMR assignments were made with the assistance of 1D-TOCSY experiments to identify each pyridine ring spin system, while individual protons within a ring were assigned on the basis of their chemical shifts and the following typical ${ }^{3} \mathrm{~J}$ coupling patterns for pyridine protons: $\mathrm{H} 3(\mathrm{~d}, J=8 \mathrm{~Hz}), \mathrm{H} 4(\mathrm{t}, J=8 \mathrm{~Hz}$ ), H5 $(\mathrm{dd}, J=8,5 \mathrm{~Hz}), \mathrm{H} 6(\mathrm{~d}, J=5 \mathrm{~Hz})$. Mass spectra were recorded using a Kratos MS80RFA mass spectrometer with a Mach 3 data system. Electron Impact (EI) spectra were obtained at $70 \mathrm{eV}$ with a source temperature of $250{ }^{\circ} \mathrm{C}$. Electrochemical measurements were performed under argon using a Bioanalytical Systems BAS 100A Electrochemical Analyser. Cyclic and differential pulse voltammograms were recorded under $\mathrm{Ar}$ in $0.02 \mathrm{M}\left[\left(n-\mathrm{C}_{4} \mathrm{H}_{9}\right)_{4} \mathrm{~N}\right] \mathrm{B}\left(\mathrm{C}_{6} \mathrm{~F}_{5}\right)_{4} / \mathrm{CH}_{3} \mathrm{CN}$ at $+25{ }^{\circ} \mathrm{C}$ using a glassy carbon working electrode, a platinum wire auxiliary electrode and an $\mathrm{Ag} / \mathrm{AgCl}\left(0.02 \mathrm{M}\left[\left(n-\mathrm{C}_{4} \mathrm{H}_{9}\right)_{4} \mathrm{~N}\right] \mathrm{B}\left(\mathrm{C}_{6} \mathrm{~F}_{5}\right)_{4}\right.$ in $\left.\mathrm{CH}_{3} \mathrm{CN}\right)$ reference electrode; or in $0.1 \mathrm{M}\left[\left(n-\mathrm{C}_{4} \mathrm{H}_{9}\right)_{4} \mathrm{~N}\right] \mathrm{PF}_{6} / \mathrm{CH}_{3} \mathrm{CN}$ using an $\mathrm{Ag} / \mathrm{AgCl}\left(0.1 \mathrm{M}\left[\left(n-\mathrm{C}_{4} \mathrm{H}_{9}\right)_{4} \mathrm{~N}\right] \mathrm{PF}_{6}\right.$ in $\left.\mathrm{CH}_{3} \mathrm{CN}\right)$ reference electrode. Ferrocene was added as an internal standard on completion of each experiment the ferrocene / ferrocenium couple $\left(\mathrm{FeCp}_{2}{ }^{+} / \mathrm{FeCp}_{2}{ }^{0}\right)$ occurred at $+550 \mathrm{mV}$ vs. $\left.\mathrm{Ag} / \mathrm{AgCl}\right\}$ : all potentials are quoted in $\mathrm{mV}$ versus $\mathrm{FeCp}_{2}{ }^{+} / \mathrm{FeCp}_{2}{ }^{0 .} .{ }^{15}$ Cyclic voltammetry was performed with a sweep rate of $100 \mathrm{mV} \mathrm{s}^{-1}$; differential pulse voltammetry was conducted with a sweep rate of $4 \mathrm{mV} \mathrm{s}^{-1}$ and a pulse amplitude, width and period of $50 \mathrm{mV}$, $60 \mathrm{~ms}$ and $1 \mathrm{~s}$, respectively. In order to obtain reasonable electrochemical response, measurements in the $0.02 \mathrm{~mol} \mathrm{dm}^{-3}$ $\left[\left(n-\mathrm{C}_{4} \mathrm{H}_{9}\right)_{4} \mathrm{~N}\right] \mathrm{B}\left(\mathrm{C}_{6} \mathrm{~F}_{5}\right)_{4} / \mathrm{CH}_{3} \mathrm{CN}$ electrolyte required a concentration of complex which was approximately double that in $0.1 \mathrm{~mol} \mathrm{dm}^{-3}\left[\left(n-\mathrm{C}_{4} \mathrm{H}_{9}\right)_{4} \mathrm{~N}\right] \mathrm{PF}_{6} / \mathrm{CH}_{3} \mathrm{CN}$.

Electronic spectra were recorded using a CARY 5E UV/Vis/NIR spectrophotometer interfaced to Varian WinUV software. The absorption spectra of the electrogenerated mixedvalence complexes $(3)^{\mathrm{n}+},(\mathbf{4})^{\mathrm{n}+}$ and $(\mathbf{9})^{\mathrm{n}+}$ were obtained in situ by the use of an Optically Semi-Transparent Thin-Layer Electrosynthetic (OSTLE) cell mounted in the path of the spectrophotometer. ${ }^{28}$ Solutions for the spectroelectrochemical experiments contained $0.1 \mathrm{M}\left[\left(n-\mathrm{C}_{4} \mathrm{H}_{9}\right)_{4} \mathrm{~N}\right] \mathrm{PF}_{6}$ or $0.02 \mathrm{M}[(n-$ $\left.\left.\mathrm{C}_{4} \mathrm{H}_{9}\right)_{4} \mathrm{~N}\right] \mathrm{B}\left(\mathrm{C}_{6} \mathrm{~F}_{5}\right)_{4}$ supporting electrolyte and the complex (ca. $0.5 \mathrm{mM}$ ) under investigation in acetonitrile. All experiments were conducted at $-35^{\circ} \mathrm{C}$ according to methods described previously. ${ }^{29}$ The near-infrared (NIR) spectra of the dinuclear systems were scaled $\mathrm{d}^{20,30}$ as $\int\{\varepsilon(v) / v\} \mathrm{d} v$ and deconvoluted by use of the software package GRAMS32.

2,2'-Pyridil (Aldrich), hexamethylenetetramine (Aldrich), benzaldehyde (Aldrich), $\mathrm{RuCl}_{3} \cdot \mathrm{H}_{2} \mathrm{O}$ (Strem, 99\%), SP Sephadex C-25 (Amersham Pharmacia Biotech) and laboratory reagent solvents were used as received. $\left[\mathrm{Ru}(\text { bpy })_{2} \mathrm{Cl}_{2}\right] \cdot 2 \mathrm{H}_{2} \mathrm{O}$ was prepared according to the literature procedure. ${ }^{31}$ Tetra- $n$ butylammonium hexafluorophosphate $\left(\left[n-\mathrm{C}_{4} \mathrm{H}_{9}\right)_{4} \mathrm{~N}\right] \mathrm{PF}_{6}$; Fluka, $99+\%$ ) was dried in vacuo at $60^{\circ} \mathrm{C}$ prior to use and acetonitrile $\left(\mathrm{CH}_{3} \mathrm{CN}\right.$; Aldrich, $\left.99.9+\%\right)$ was distilled over $\mathrm{CaH}_{2}$ before use. $\left[\left(n-\mathrm{C}_{4} \mathrm{H}_{9}\right)_{4} \mathrm{~N}\right] \mathrm{B}\left(\mathrm{C}_{6} \mathrm{~F}_{5}\right)_{4}{ }^{16}$ was prepared by metathesis from lithium tetrakis(pentafluorophenyl)borate $\left(\mathrm{LiB}\left(\mathrm{C}_{6} \mathrm{~F}_{5}\right)_{4} \cdot \mathrm{Et}_{2} \mathrm{O} ; \quad\right.$ Boulder Scientific) as described previously. ${ }^{32}$

\section{Syntheses}

\section{Preparation of 4,5-di(2-pyridyl)imidazole.}

Hexamethylenetetramine $\left(0.13 \mathrm{~g}, 9.27 \times 10^{-4} \mathrm{~mol}\right)$ was added to a solution of $2,2^{\prime}$-pyridil $\left(1.10 \mathrm{~g}, 5.18 \times 10^{-3} \mathrm{~mol}\right)$ and a tenfold excess of ammonium acetate $\left(4 \mathrm{~g}, 5.18 \times 10^{-2} \mathrm{~mol}\right)$ in acetic acid $(25 \mathrm{~mL})$. The mixture was refluxed for 1 hour and subsequently allowed to cool to room temperature. The dark mixture was diluted with water $(25 \mathrm{~mL})$ and neutralised with ammonium hydroxide solution and was then filtered through Celite to yield a green solution. The green solution was extracted with $\mathrm{CH}_{2} \mathrm{Cl}_{2}(3 \times 25 \mathrm{~mL})$, the combined organic fractions were dried over sodium sulfate and the solvent removed to yield a dark tarry residue containing both the desired product and a second product containing an imidazolo[1,5-a]pyridine ring system. The mixture was purified by column chromatography on silica eluting with $10 \% \mathrm{MeOH}$ in $\mathrm{CHCl}_{3}$ to yield a pale brown oil which solidified on standing. Yield $0.15 \mathrm{~g},(13 \%)$. EI mass spectrum: calc. $\mathrm{m} / \mathrm{z}$ for $\mathrm{C}_{13} \mathrm{H}_{10} \mathrm{~N}_{4} 222$; found 221 . ${ }^{1} \mathrm{H}$ NMR $\left(\mathrm{CDCl}_{3}\right) \delta: 8.58(2 \mathrm{H}, \mathrm{d}, \mathrm{H} 6) ; 8.34(2 \mathrm{H}, \mathrm{bs}, \mathrm{H} 3) ; 7.73(3 \mathrm{H}, \mathrm{m}, \mathrm{H} 4$, $\mathrm{H} 2) ; 7.18$ (2H, t, H5).

\section{Preparation of 4,5-di(2-pyridyl)-2-phenylimidazole}

Benzaldehyde $\left(0.375 \mathrm{~g}, 3.53 \times 10^{-3} \mathrm{~mol}\right)$ was added to a solution of 2,2'-pyridil $\left(0.75 \mathrm{~g}, 3.53 \times 10^{-3} \mathrm{~mol}\right)$ and ammonium acetate $\left(2.72 \mathrm{~g}, 3.53 \times 10^{-2} \mathrm{~mol}\right)$ in acetic acid $(10 \mathrm{~mL})$. The mixture was heated in a microwave for 5 minutes $(5 \times 1$ minute with swirling of the flask between periods of heating). The reaction mixture was allowed to cool to room temperature and neutralised with conc. ammonia solution. The pale yellow precipitate that formed was collected and washed with water and a small amount of cold ethanol, to afford the desired product in $46 \%$ yield $\left(0.48\right.$ g). EI mass spectrum: calc. $\mathrm{m} / \mathrm{z}$ for $\mathrm{C}_{19} \mathrm{H}_{14} \mathrm{~N}_{4}$ 298; found 297. ${ }^{1} \mathrm{H}$ NMR $\left(\mathrm{CDCl}_{3}\right) \delta: 8.60(2 \mathrm{H}, \mathrm{d}, \mathrm{H} 6) ; 8.33(2 \mathrm{H}$, br s, H3); 8.02 (2H, d, Hortho); 7.83 (2H, t, H4); 7.45 (2H, t, Hmeta); 7.38 (1H, t, Hpara); 7.20 (2H, t, H5). 


\section{Preparation and separation of rac and meso} $\left[(\text { bpy })_{2} \mathrm{Ru}(\mu-7) \mathrm{Ru}(\mathrm{bpy})_{2}\right]\left(\mathrm{PF}_{6}\right)_{3},(9$ rac $)$ and $(9$ meso $)$

$\left[\mathrm{Ru}(\mathrm{bpy})_{2} \mathrm{Cl}_{2}\right] \cdot 2 \mathrm{H}_{2} \mathrm{O}\left(66.0 \mathrm{mg}, 1.28 \times 10^{-4} \mathrm{~mol}\right)$ was added to a suspension of 4,5-di(2-pyridyl)imidazole (19.0 mg, $6.38 \times 10^{-5}$ mol) in ethylene glycol $(2.5 \mathrm{~mL})$ and 2 drops of conc. $\mathrm{NaOH}$. The mixture was heated in a microwave for 2 minutes in $20-30$ second intervals swirling the flask between each period of heating. The dark red-brown mixture was cooled to room temperature and water $(5 \mathrm{~mL})$ added. The desired complex was isolated as the hexafluorophosphate salt by addition of an excess of an aqueous saturated ammonium hexafluorophosphate solution. The dark precipitate was collected by suction filtration and washed with water. The complex was purified by converting to the chloride salt by stirring in water with Amberlite resin IRA $-400(\mathrm{Cl})$ for $20 \mathrm{mins}$ and any mononuclear compound removed by gradient elution on SP Sephadex C-25 with $\mathrm{NaCl}$ solution $(0.125 \mathrm{M}-0.50 \mathrm{M})$. The product was precipitated by addition of saturated ammonium hexafluorophosphate solution, and collected by filtration.

The rac and meso isomers were readily separated by cation exchange chromatography. The hexafluorophosphate salt was converted to the chloride salt by stirring in water with excess Amberlite anion exchange resin. The aqueous solution was loaded on a Sephadex column and eluted with $0.2 \mathrm{M}$ sodium 4toluenesulfonate solution, the rac isomer being eluted first. The two red fractions were precipitated by addition of potassium hexafluorophosphate. The resultant solids were purified by dissolution in acetone and adsorption on a short silica plug, washed with water and acetone, and then removed from the silica gel with a $5 \%$ solution of ammonium hexafluorophosphate in acetone. The complexes were isolated by the addition of water and partial removal of the solvent under reduced pressure. The red precipitate that formed was collected by filtration and dried in vacuo. Yield, $72.8 \mathrm{mg}\left(3.31 \times 10^{-5} \mathrm{~mol}, 77 \%\right)$. For NMR data see Figure 2 and Table 2.

\section{Preparation of $\left[(\mathrm{bpy})_{2} \mathrm{Ru}(\mu-8) \mathrm{Ru}(\mathrm{bpy})_{2}\right]\left(\mathrm{PF}_{6}\right)_{3},(10$ meso $)$}

$\left[\mathrm{Ru}(\mathrm{bpy})_{2} \mathrm{Cl}_{2}\right] \cdot 2 \mathrm{H}_{2} \mathrm{O}\left(55.0 \mathrm{mg}, 1.07 \times 10^{-4} \mathrm{~mol}\right)$ was added to a suspension of 4,5-di(2-pyridyl)-2-phenylimidazole $(13.5 \mathrm{mg}$, $\left.4.53 \times 10^{-5} \mathrm{~mol}\right)$ in ethylene glycol $(2.5 \mathrm{~mL})$ and 2 drops of conc. $\mathrm{NaOH}$ added. The mixture was heated in a microwave for 2 minutes in $20-30$ second intervals swirling the flask between each heating. The dark red brown mixture was cooled to room temperature and water $(5 \mathrm{~mL})$ added. The desired complex was isolated as the hexafluorophosphate salt by addition of an excess of an aqueous saturated ammonium hexafluorophosphate solution. The dark precipitate was collected by suction filtration and washed with water. The crude compound was first purified by column chromatograph on alumina using $10 \% \mathrm{MeOH}$ in $\mathrm{CHCl}_{3}$ as the eluent. The complex was separated from any mononuclear species or free ligand by conversion to the chloride salt with Amberlite resin IRA-400(Cl) for 20 mins. Any mononuclear compound was removed by gradient elution on Sephadex SP C-25 with $\mathrm{NaCl}$ solution $(0.125 \mathrm{M}-0.50 \mathrm{M})$. The product was precipitated by addition of saturated ammonium hexafluorophosphate solution, and collected by filtration. The red precipitate was dissolved in a small amount of acetone, which was adsorbed onto a short silica column, washed with water $(4 \mathrm{~mL})$ and removed from the silica gel with a $5 \%$ solution of ammonium hexafluorophosphate in acetone. Water was added to the complex-containing acetone solution and the solvent partially removed under reduced pressure. The residue was then collected by filtration, washed with water and dried under vacuum. Yield $31.1 \mathrm{mg}\left(1.99 \times 10^{-5} \mathrm{~mol}, 44 \%\right)$. For NMR data see Table 2 .

\section{X-ray crystallography}

The crystal data, data collection and refinement parameters for compounds (9rac), (9meso) and (10meso) are given in Table 5. Measurements were made with a Siemens CCD area detector using graphite monochromatised $\mathrm{Mo} \mathrm{K} \alpha(\lambda=0.71073 \AA)$ radiation. The intensities were corrected for Lorentz and polarisation effects and for absorption. ${ }^{33}$ The structures were solved by direct methods using SHELXS, ${ }^{34}$ and refined on $F^{2}$ using all data by full-matrix least-squares procedures using SHELXL-97. ${ }^{35}$ Due to the weakness of the data from these small crystals many of the atoms in each structure were restrained to approximate to isotropic behaviour. Hydrogen atoms were included in calculated positions with isotopic displacement parameters 1.2 times the isotropic equivalent of their carrier carbon atoms. The functions minimised were $\Sigma w\left(F_{\mathrm{o}}^{2}-F_{\mathrm{c}}{ }^{2}\right)$, with $w=\left[\sigma^{2}\left(F_{\mathrm{o}}{ }^{2}\right)+\mathrm{a} P^{2}+\mathrm{b} P\right]^{-1}$, where $P=\left[\max \left(F_{\mathrm{o}}\right)^{2}+2 F_{\mathrm{c}}{ }^{2}\right] / 3$.

Crystallographic data, as CIF files, have been deposited with the Cambridge Crystallographic Data Centre (CCDC Nos 271748-271750). Copies can be obtained free of charge from: The Director, CCDC, 12 Union Road, Cambridge CB2 1EZ, U.K. (e-mail: deposit@ccdc.cam.ac.uk).

Table 5 X-ray crystal data.

\begin{tabular}{|c|c|c|c|}
\hline Compound & 9rac & 9meso & 10meso \\
\hline Formula & $\begin{array}{l}\mathrm{C}_{53} \mathrm{H}_{41} \mathrm{~F}_{18} \mathrm{~N}_{12^{-}} \\
\mathrm{OP}_{3} \mathrm{Ru}_{2}\end{array}$ & $\begin{array}{l}\mathrm{C}_{65.5} \mathrm{H}_{56} \mathrm{~F}_{18} \mathrm{~N}_{13^{-}} \\
\mathrm{P}_{3} \mathrm{Ru}_{2}\end{array}$ & $\begin{array}{l}\mathrm{C}_{62.5} \mathrm{H}_{49} \mathrm{~F}_{18} \mathrm{~N}_{12}- \\
\mathrm{P}_{3} \mathrm{Ru}_{2}\end{array}$ \\
\hline Formula Weight & 1499.03 & 1662.28 & 1605.19 \\
\hline Crystal System & trigonal & triclinic & orthorhombic \\
\hline$a(\AA)$ & $14.031(1)$ & $12.585(6)$ & $26.890(2)$ \\
\hline$b(\AA)$ & $14.031(1)$ & $13.339(7)$ & $11.609(1)$ \\
\hline$c(\AA)$ & $54.000(10)$ & $22.104(12)$ & $43.684(3)$ \\
\hline$\alpha\left(^{\circ}\right)$ & 90 & $73.085(9)$ & 90 \\
\hline$\beta\left({ }^{\circ}\right)$ & 90 & $81.326(10)$ & 90 \\
\hline$\gamma\left({ }^{\circ}\right)$ & 120 & $62.856(9)$ & 90 \\
\hline $\mathrm{V}\left(\AA^{3}\right)$ & $9206(2)$ & $3159(3)$ & $13636(2)$ \\
\hline Space Group & $P 3_{1} 21$ & $P-1$ & Cmca \\
\hline Z & 6 & 2 & 8 \\
\hline $\mathrm{D}_{\mathrm{c}}\left(\mathrm{Mg} \mathrm{m}^{-3}\right)$ & 1.622 & 1.748 & 1.564 \\
\hline $\mathrm{F}(000)$ & 4476 & 1670 & 6424 \\
\hline Temperature (K) & $163(2)$ & $93(2)$ & $163(2)$ \\
\hline Crystal Form & red plate & red needle & red rod \\
\hline$\mu\left(\mathrm{mm}^{-1}\right)$ & 0.674 & 0.664 & 0.611 \\
\hline $2 \theta_{\max }\left({ }^{\circ}\right)$ & 50 & 50 & 50 \\
\hline Data collected & 63993 & 22821 & 47350 \\
\hline Unique data & 10749 & 10548 & 6166 \\
\hline Parameters & 822 & 962 & 516 \\
\hline $\mathrm{R}^{\mathrm{a}}[\mathrm{I}>2 \sigma(\mathrm{I})]$ & 0.0560 & 0.0860 & 0.0826 \\
\hline wR $^{\mathrm{b}}$ (all data) & 0.0849 & 0.2176 & 0.2551 \\
\hline
\end{tabular}

$\left.{ }^{\mathrm{a}} \mathrm{R}=\sum\left|\mathrm{F}_{\mathrm{o}}\right|-\left|\mathrm{F}_{\mathrm{c}}\right|\right) / \Sigma\left|\mathrm{F}_{\mathrm{o}}\right| . \quad{ }^{\mathrm{b}} \mathrm{wR}=\left(\sum\left[\mathrm{w}\left(\mathrm{F}_{\mathrm{o}}{ }^{2}-\mathrm{F}_{\mathrm{c}}{ }^{2}\right)^{2}\right] / \Sigma\left[\mathrm{w}\left(\mathrm{F}_{\mathrm{o}}{ }^{2}\right)^{2}\right]\right)^{1 / 2}$. 


\section{Acknowledgements}

We thank the Australian Research Council, the Royal Society of New Zealnd Marsden Fund and the University of Canterbury for financial support of this work.

\section{References}

1 (a) P. J. Steel, Coord. Chem. Rev., 1990, 106, 227; (b) A. Juris, V. Balzani, F. Barigelletti, S. Campagna, P. Belser and A. von Zelewsky, Coord. Chem. Rev., 1988, 84, 85; (c) S. Swavey and K. J. Brewer, in "Comprehensive Coordination Chemistry II", (Eds J. A McCleverty and T. J. Meyer), Vol. 1, p135, Elsevier, Oxford, 2004.

2 V. Balzani, A. Juris, M. Venturi, S. Campagna and S. Serroni, Chem. Rev., 1996, 96, 759.

3 C. Kaes, A. Katz and M. W. Hosseini, Chem. Rev., 2000, 100, 3553.

4 (a) D. P. Rillema and K. B. Mack, Inorg. Chem., 1982, 21, 3849; (b) S. D. Ernst and W. Kaim, Inorg. Chem., 1989, 28, 1520; (c) D. A. Reitsma and F. R. Keene, J. Chem. Soc., Dalton Trans., 1993, 2859.

5 (a) S. D. Ernst, W. Kasack and W. Kaim, Inorg. Chem., 1988, 27, 1146; (b) L. S. Kelso, D. A. Reitsma and F. R. Keene, Inorg. Chem., 1996, 35, 5144; (c) K. Kalyanasundaram and Md. K. Nazeeruddin, Inorg. Chem., 1990, 29, 1888; (d) B. D. Yeomans, L. S. Kelso, P. A. Tregloan and F. R. Keene, Eur. J. Inorg. Chem., 2001, 239.

6 (a) C. Richardson and P. J. Steel, Dalton Trans., 2003, 992; (b) D. M. D'Alessandro, F. R. Keene, P. J. Steel and C. J. Sumby, Aust. J. Chem., 2003, 56, 657; (c) A. J. Downard, I. G. Phillips and P. J. Steel, Aust. J. Chem., 2004, 57, 865; (d) P. J. Steel, Molecules, 2004, 9, 440; (e) P. J. Steel, Acc. Chem. Res., 2005, 38, 243.

7 C. Richardson, P. J. Steel, D. M. D'Alessandro, P. C. Junk and F. R. Keene, J. Chem. Soc., Dalton Trans., 2002, 2775.

8 G. Denti, S. Campagna, L. Sabatino, S. Serroni, M. Ciano and V. Balzani, Inorg. Chem., 1990, 29, 4750.

9 I. G. Phillips and P. J. Steel, Aust. J. Chem., 1998, 51, 371.

10 W. Langenbeck, G. Reinisch and K. Schonzart, Chem. Ber., 1959, 92, 2040.

11 J. Wang, R. Mason, D. VanDerveer, K. Feng and X. R. Bu, J. Org. Chem., 2003, 68, 5415.

12 S. E. Wolkenberh, D. D. Wisnoski, W. H. Leister, Y. Wang, Z. Zhao and C. W. Lindsley, Org. Lett., 2004, 6, 1453.

13 J. Elguero, C. Marzin, A. R. Katritzky and P. Linda, 'The Tautomerism of Heterocycles' Adv. Heterocycl. Chem., Suppl. 1, 1976.

14 N. C. Fletcher, P. C. Junk, D. A. Reitsma and F. R. Keene, J. Chem. Soc., Dalton Trans., 1998, 133.

15 F. R. Keene, Chem. Soc. Rev., 1998, 27, 185.

16 R. LeSuer and W. E. Geiger, Angew. Chem. Int. Ed., 2000, 39, 248.

17 D. M. D'Alessandro and F. R. Keene, Dalton Trans., 2004, 3950.

18 K. Kalyanasundaram, S. M. Zakeeruddin, and M. K. Nazeeruddin, Coord. Chem. Rev., 1994, 132, 259.

19 a) R. Hage, A. H. J. Dijkhuis, J. G. Haasnoot, R. Prins, J. Reedijk, B. E. Buchanan, and J. G. Vos, Inorg. Chem., 1988, 27, 2185; (b) R. Hage, J. G. Haasnoot, H. A. Nieuwenhuis, J. Reedijk, D. J. A. De Ridder, and J. G. Vos, J. Am. Chem. Soc., 1990, 112, 9245; (c) L. De Cola, F. Barigelletti, V. Balzani, R. Hage, J. G. Haasnoot, J. Reedijk, and J. G. Vos, Chem. Phys. Lett., 1991, 178, 491; (d) R. Hage, J. G. Haasnoot, J. Reedijk, R. Wang, and J. G. Vos, Inorg. Chem., 1991, 30, 3263; (e) H. P. Hughes, D. Martin, S. Bell, J. J. McGarvey, and J. G. Vos, Inorg. Chem., 1993, 32, 4402.

20 (a) N. S. Hush, Progr. Inorg. Chem., 1967, 8, 391; (b) N. S. Hush, Electrochim. Acta, 1968, 13, 1005.

21 M. B. Robin and P. Day, Adv. Inorg. Chem. Radiochem., 1967, 10, 247.

22 K. D. Demadis, C. M. Hartshorn, and T. J. Meyer, Chem. Rev., 2001, 101, 2655.

23 E. M. Kober and T. J. Meyer, Inorg. Chem., 1983, 22, 1614.

24 (a) L.-T. Zhang, J. Ko, and M. J. Ondrechen, J. Phys. Chem., 1989, 93, 3030; (b) L. J. Root and M. J. Ondrechen, Chem. Phys. Letters, 1982, 93, 421; (c) J. Ko and M. J. Ondrechen, Chem. Phys. Letters, 1984, 112, 507; (d) M. J. Ondrechen, J. Ko, and L. J. Root, J. Phys. Chem., 1984, 88, 5919; (e) J. Ko and M. J. Ondrechen, J. Am. Chem. Soc., 1985, 107, 6161; (f) M. J. Ondrechen, J. Ko, and L.-T. Zhang, J. Am. Chem. Soc., 1987, 109, 1672; (g) L.-T. Zhang, J. Ko, and M. J. Ondrechen, J. Am. Chem. Soc., 1987, 109, 1666.
25 G. P. Bean, J. Org. Chem., 1998, 63, 2497.

26 (a) M. D. Lowery, W. S. Hammack, H. G. Drickamer, and D. N. Hendrickson, J. Am. Chem. Soc., 1987, 109, 8019; (b) J. T. Hupp, G. A. Neyhart, T. J. Meyer, and E. M. Kober, J. Phys. Chem., 1992, 96, 10820; (c) N. A. Lewis, Y. S. Obeng, and W. L. Purcell, Inorg. Chem., 1989, 28, 3796; (d) N. A. Lewis and Y. S. Obeng, J. Am. Chem. Soc., 1988, 110, 2306; (e) D. M. D'Alessandro, P. C. Junk, and F. R. Keene, Supramol. Chem., 2005, in the press.

27 (a) P. Pereztejeda, P. Neto-Ponce, and F. Sánchez, J. Chem. Soc., Dalton Trans., 2001, 1686; (b) R. L. Blackbourn, Y. Dong, L. A. Lyon, and J. T. Hupp, Inorg. Chem., 1994, 33, 4446.

28 C. M. Duff and G. A. Heath, Inorg. Chem., 1991, 30, 2528.

29 D. M. D'Alessandro and F. R. Keene, Chem. Eur. J., 2005, 11, 3679.

30 J. R. Reimers and N. S. Hush, Inorg. Chem., 1990, 29, 3686.

31 B. P. Sullivan, D. J. Salmon and T. J. Meyer, Inorg. Chem. 1978, 17, 3334.

32 D. M. D'Alessandro and F. R. Keene, Chem. Phys., 2005, in the press.

33 G. M. Sheldrick, SADABS, University of Göttingen, Germany, 1998.

34 G. M. Sheldrick, Acta Cryst., 1990, A46, 467.

35 G. M. Sheldrick, SHELXL-97, University of Göttingen, Germany, 1997. 
